\title{
Correction to: Genome-wide association studies of bark texture in Populus trichocarpa
}

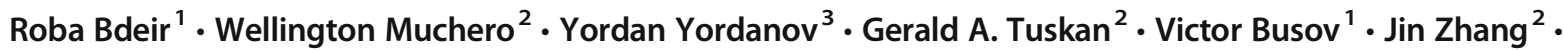 \\ Oliver Gailing ${ }^{1,4}$
}

Published online: 29 November 2019

(C) Springer-Verlag GmbH Germany, part of Springer Nature 2019

\section{Correction to: Tree Genetics \& Genomes (2019) 15: 14} https://doi.org/10.1007/s11295-019-1320-2

The co-author Jin Zhang was unintentionally forgotten on the original author list.

The correct author list is presented in this correction.

The online version of the original article can be found at https://doi.org/ $10.1007 / \mathrm{s} 11295-019-1320-2$

$\triangle$ Oliver Gailing

ogailing@mtu.edu; ogailin@gwdg.de

1 School of Forest Resources and Environmental Science, Michigan Technological University, 1400 Townsend Drive,

Houghton, MI 49931, USA

2 Biosciences Division, Oak Ridge National Laboratory, 1 Bethel Valley Road, Oak Ridge, TN 37831, USA

3 Department of Biology, Eastern Illinois University, 600 Lincoln Ave, Charleston, IL 61920, USA

4 Present address: Forest Genetics and Forest Tree Breeding, Faculty of Forest Sciences and Forest Ecology, University of Göttingen,

Büsgenweg 2, 37077 Göttingen, Germany 